cheaper service. These changes occurred particularly in diagnostic services, which were excluded from our analysis. Several practices were offered cheaper contracts by private hospitals for pathology and radiology services, but none of the study practices took this up.

Two practices used different provider units in phase 2 for individual specialties: in both cases this involved arranging for consultants from the new provider units (in orthopaedics and urology) to see patients on the practice premises. Others managed to negotiate favourable terms with their existing providers, thus achieving savings without affecting referral patterns. Some arranged for consultants to hold clinics on the practice premises, thus improving access for their patients but not necessarily achieving a cost saving. Others increased provision of minor surgery with a view to reducing referrals to certain specialties. Many hoped to achieve a reduction in numbers of follow up appointments. However, for the most part the fundholders' business plans indicated that they planned to make savings in the prescribing element of their budgets rather than in hospital services.

Another factor which may have been important in this first year of the reforms was the determination of these pioneering fundholders to ensure the success of the scheme. There is no doubt that they were sincere in their belief that their patients would benefit from their involvement. ${ }^{2}$ Many had faced hostility from colleagues who were opposed to fundholding. The government was also particularly anxious in an election year to ensure both that the benefits of the scheme were recognised and that accusations that they were encouraging the development of a two tier service were not substantiated. Thus it seems likely that health authorities were encouraged to be generous in the allocation of budgets, that fundholders were less concerned than they might otherwise have been about the need to stay within strict cash limits, and that nonfundholders were allowed greater freedom of referral than might have been anticipated.

\section{Conclusion}

The overall increase in referral rates may seem disappointing to those who hoped that fundholding would provide a mechanism for reducing the demand for specialist care, but it was probably unrealistic to expect a shift to occur in the first year of the scheme. Although we found no evidence that the referral behaviour of first wave fundholders was affected by budgetary pressures, this may not be indicative of the way in which the effects of the reforms will be felt in the next few years. It will be important to continue to monitor these effects.

We are very grateful to the general practitioners, their practice managers, and support staff, without whom this study would not have been possible. The study was funded by the Oxford Regional Health Authority.

1 Secretaries of State for Health, Wales, Northern Ireland, and Scotland. Working for patients. London: HMSO, 1989.

2 Glennerster H, Matsaganis M, Owens P. A foothold for fundholding. London: King's Fund Institute, 1992.

3 Bain J. Budget holding in Calverton: one year on. BMf 1992;304:971-3.

4 Roland M. Fundholding and cash limits in primary care: blight or blessing? BM7 1991;303:171-2.

5 Roland M, Coulter A, eds. Hospital referrals. Oxford: Oxford University Press, 1992.

6 Coulter A. Fundholding general practices. BMF 1992;304:397-8.

7 Bradlow J, Coulter A, Brooks P. Patterns of referral. Oxford: University of Oxford Health Services Research Unit, 1992.

8 Gardner MJ, Altman DG. Statistics with confidence. London: British Medical Journal, 1990 .

9 Coulter A, Seagroatt V, McPherson K. Relation between general practices' outpatient referral rates and rates of elective admission to hospital. $B M$ 1990;301:273-6.

10 Department of Health. Funding general practice: the programme for the introduction of general practice budgets. London: Department of Health, 1989.

(Accepted 16 December 1992)

\title{
Screen detected high blood pressure under 40: a general practice population followed up for 21 years
}

Medical Research Council Epidemiology and Medical Care Unit, Northwick Park and Glyncorrwg Health Centre, West Glamorgan SA13 3BL

Julian Tudor Hart, general practitioner

Glyncorrwg Health Centre, West Glamorgan SA13 3BI Catherine Edwards, practice manager

Mary Hart, research team leader

Janet Jones, practice nurse Margaret Jones, practice nurse

University College London Medical School

Andrew Haines, professor of

primary health care

Department of Public

Health, University of

Glasgow

Graham Watt, senior lecturer

Correspondence to:

DrJ T Hart.

BMF 1993;306:437-40

Julian Tudor Hart, Catherine Edwards, Mary Hart, Janet Jones, Margaret Jones, Andrew Haines, Graham Watt

\section{Abstract}

Objective-To assess hypertension detected under 40 in a general practice population.

Design-Prospective case-control study.

Setting and subjects-Former coal mining community in south Wales. Systematic case finding for hypertension and associated risk factors applied to a mean total population of 1945 from age 20 on a five year cycle through 21 years. Mean population aged 20-39, 227 men and 213 women. Case criteria: age $<40$ and mean systolic pressure $\geqslant 160 \mathrm{~mm} \mathrm{Hg}$ or diastolic pressure $\geqslant 100 \mathrm{~mm} \mathrm{Hg}$. Age and sex matched controls randomly sampled from the same population.

Main outcome measures-Mean initial pressures and pressures at follow up in 1989 or preceding death, and all cardiovascular events.

Results-25 men and 16 women met criteria. Estimated five yearly inceptions were $26 / 1000$ for men and 18/1000 for women. Male group mean initial blood pressure was $164 / 110 \mathrm{~mm} \mathrm{Hg}$ for cases, falling to $148 / 89 \mathrm{~mm} \mathrm{Hg}$ at follow up. Five male cases died at mean age $47 \cdot 8$, compared with two controls at 49.5. Female group mean initial pressure was
$172 / 107 \mathrm{~mm} \mathrm{Hg}$ for cases, falling to $145 / 86 \mathrm{~mm} \mathrm{Hg}$ at follow up. One female case died aged 50, no controls. 10 male cases had non-fatal cardiovascular events at mean age 40.2 , compared with two controls at mean age 50.5. Four female cases had non-fatal events at mean age 47.2, compared with one control aged 58 . Male differences were statistically significant.

Conclusions-Hypertension under 40 is dangerous, commoner in men than women, rarely secondary to classic causes, and may be controlled in general practice on a whole community basis.

\section{Introduction}

Primary hypertension usually begins early in life. Measurements are unstable and poorly predictive in adolescence, ${ }^{1}$ but from 20 years individual variability seems to be less and does not increase with age. ${ }^{2}$ Failure of antihypertensive treatment substantially to reduce coronary risk may partly be attributable to late intervention, after vascular changes are less easily reversible.

Measurement of blood pressure in young adults, though required by the new general practitioner contract every three years from April 1991, is still not 
established practice. As recently as 1991 at least one authority still questioned the value of routine measurement of blood pressure under $35 .^{3}$ In 1974 , in seven randomly sampled London practices, Heller and Rose found blood pressure recorded in only $10 \%$ of men and $18 \%$ of women aged $20-39 .{ }^{4}$ By 1982 , in 23 randomly sampled London general practices Kurji and Haines found blood pressure recorded in $28 \%$ of men and $61 \%$ of women aged 30-39.5 By 1986, in 5123 randomly sampled men in Scotland Smith et al found blood pressure recorded in $52 \%$ of general practitioners' records for men aged $40-44$, rising to $74 \%$ of those aged 55-59. ${ }^{6}$ Though high blood pressure is a treatable risk with a higher prevalence ${ }^{2}$ and mortality in young men than young women, that study showed that even in the age group 40-44 young women were still more than twice as likely to be detected as men.

The British regional heart study showed that men in heavy industrial areas generally have higher group mean arterial pressures than men in rural or nonindustrial urban areas. ${ }^{7}$ Mortality from coronary heart disease and stroke is exceptionally high in young men in the south Wales industrial valleys, with rates similar to those in the west of Scotland. ${ }^{89}$

A screening programme for high blood pressure and related risks, begun in 1968 and sustained for 21 years in a defined community ${ }^{10}$ gave us an opportunity to study long term management of high blood pressure in young adults in a social context, with data collected prospectively on originally unsuspected associations. Retrospectively, we became interested in the possibility that high alcohol intake, ${ }^{11}{ }^{12}$ oral contraception, ${ }^{13}$ and obesity ${ }^{14}$ might be important and treatable causes under 40 .

\section{Population and methods}

Glyncorrwg is a former coal mining village in south Wales. At 206 on the Townsend index for social deprivation it is in the worst $5 \%$ of all electoral wards in Wales, chiefly because of high male unemployment. Over $85 \%$ of the male population are or were manual workers.

Starting in 1968, the whole adult population registered with the Glyncorrwg practice was screened for hypertension by a system of case finding supplemented by call up on a five year cycle. ${ }^{10} 16$ This roughly doubled the number of known and treated hypertensives in the practice. Response rates varied from $98 \%$ in $1968-70^{10}$ to about $90 \%$ in subsequent five year spans. This policy was applied to a stable population of 2100 (all ages) in 1968, steadily declining through out migration and falling family size to 1790 ( 895 males and 895 females) by 1989 . There were 310 male and 248 female deaths, 528 male and 578 female out migrants or transfers of care, and 750 male and female in migrants or accessions to the practice list from 1968 to 1989 . The proportion of young people increased; in 1968 there were 205 men and 194 women aged $20-39$, rising to 250 men and 233 women by 1985 .

For people under 40 hypertension was defined as a mean arterial systolic pressure of $160 \mathrm{~mm} \mathrm{Hg}$ or more or diastolic pressure of $100 \mathrm{~mm} \mathrm{Hg}$ or more (diastolic phase V), derived from three readings on separate days. A random zero sphygmomanometer was used for almost all measurements, and outsize cuffs were used when indicated by arm girth. All cases, including out migrants, were followed up in 1989 , and deaths were included in the analysis.

Controls matched for age and sex were drawn randomly from the same population at risk, including deaths, out migrants, and in migrants. Controls were rejected if blood pressures of $160 / 100 \mathrm{~mm} \mathrm{Hg}$ or more were ever recorded under 40 , or $170 / 105 \mathrm{~mm} \mathrm{Hg}$ thereafter. Records had been retained for deaths, out migrants, and secessions from the list, with summaries sent to new doctors. Together with records for the current population these were searched for routinely recorded data on arterial pressure, smoking, body mass index (weight $(\mathrm{kg}$ ) divided by squared height $\left(\mathrm{m}^{2}\right)$ ), oral contraceptive use, and either stated alcohol intake or social, haematological, or biochemical evidence of alcohol damage. Stated weekly alcohol intakes of 36 units or more were regarded as excessive, but all cases with high intake had other social or biochemical evidence of damage at some time. These data were compared in the hypertensive and normotensive groups, as nearly as possible to the same ages at which these data had been recorded for hypertensive cases. Periods at risk under 40 were obviously shorter for both in migrants and out migrants and deaths than for people permanently resident throughout the study.

All young hypertensives, currently treated or untreated with antihypertensive drugs, were included in the analysis and are included in the results on an intention to treat basis. Where appropriate differences between cases when found and in 1989, and between cases and controls, were compared by Student's $t$ test and a $2 \times 2$ contingency table for $\chi^{2}$ with Yates's correction.

\section{Results}

Twenty five men and 16 women met our criteria. Mean age at ascertainment of hypertension was 31.4 years for men (range 22-39) and 33.3 years for women (range 17-39). Group mean initial pressure for three ascertainment readings in the hypertensives was $165 / 110 \mathrm{~mm} \mathrm{Hg}$ for men and $172 / 107 \mathrm{~mm} \mathrm{Hg}$ for women, and $128 / 79$ and $124 / 78 \mathrm{~mm} \mathrm{Hg}$ respectively for controls.

Five male and six female hypertensives were never treated with antihypertensive drugs-four because pressure fell when a cause was removed (one was given a renal transplant and three stopped oral contraception), four because patients refused, and three because no treatment programme was ever organised (one of these died of intercurrent disease soon after diagnosis, and the other two both had predominant alcohol problems). The other 20 men and 10 women started antihypertensive medication at mean ages of 35.5 and 40.8 years respectively; many patients were observed for long periods before starting medication, especially in the early 1970s. Based on the last three measurements before medication, mean pretreatment pressure was $172 / 112 \mathrm{~mm} \mathrm{Hg}$ for men and $176 / 111 \mathrm{~mm} \mathrm{Hg}$ for women.

At follow up in 1989 group means derived from the last three readings available for all hypertensives had fallen to $148 / 88 \mathrm{~mm} \mathrm{Hg}$ for men and $145 / 86 \mathrm{~mm} \mathrm{Hg}$ for women (all changes $p<0.001$ ). In both male and female controls systolic pressures rose significantly $(p<0.001)$ from 128 to $134 \mathrm{~mm} \mathrm{Hg}$ and from 124 to $131 \mathrm{~mm} \mathrm{Hg}$ respectively, but there was no significant change in diastolic pressure (79 and $78 \mathrm{~mm} \mathrm{Hg}$ respectively on both occasions).

Of the 25 hypertensive men, by 1989 five had died at mean age 47.8 (range 40-54) years, four of cardiovascular or cerebrovascular disease and one of colorectal cancer. Symptomatic coronary, cerebrovascular, or peripheral arterial disease developed in 10 of the 25 at mean age 40.2 (range $32-53$ ) years. Of male controls, one died at age 40 of acute alcohol poisoning, one died of motor neurone disease, one had a non-fatal coronary thrombosis at age 47 , and one had vertebrobasilar insufficiency at 53. Differences for cardiovascular death were significant $(p<0 \cdot 10)$ and for morbidity highly significant $(\mathrm{p}<0.001)$.

Of the 16 hypertensive women, one died aged 49 from drowning related to alcohol; advanced coronary 
disease was found at necropsy, which also confirmed a coronary thrombosis one year previously. Symptomatic coronary, cerebrovascular, or peripheral arterial disease developed in four cases at mean age $47 \cdot 2$ (range 40-56) years, and one control had a minor stroke at age $58(\mathrm{p}<0 \cdot 10)$. No female controls died.

\section{SECONDARY CAUSES}

Causes of secondary hypertension were sought in all cases, including estimations of urine vanillylmandelic acid at periods of peak pressure or anxiety, plasma potassium, urea, and creatinine concentrations, and searches for bacteriuria and signs of coarctation or renal artery stenosis. No such abnormalities were found except for one man with end stage renal failure from ureteric obstruction undetected in infancy, in whom the presenting sign was proteinuria rather than high blood pressure.

There was no significant difference between cases and controls in oral contraceptive use: 12 of the 16 hypertensive women had recorded use of oral contraceptives compared with 13 of the 16 controls. Nonusers had been positively recorded as such in both groups. For users only, mean age at first prescription was $28 \cdot 2$ years for hypertensives (range 17-37). These high mean ages at onset and the absence of difference in uptake between hypertensives and controls reflect the history of oral contraception, which became available in the early 1960s and made rapid progress in this village, with our support. From careful analysis of recorded associations between individual arterial pressures and oral contraceptive prescription and withdrawal, oral contraception seemed to be a probable sole cause in three in whom pressure fell permanently after stopping the tablets and a probable contributory cause for another three whose blood pressures fell on withdrawal but subsequently showed a sustained rise.

Evidence of present or past excessive alcohol intake was found in 13 young hypertensive men, an impressive figure until we examined records for male controls; 13 of the 25 had similar evidence. Four young hypertensive women had present or past excessive alcohol intake, compared with one control $(p<0 \cdot 10)$. Group mean stated intakes were 46 units/week in male cases compared with 40 units/week in controls.

As expected, young hypertensives were substantially more obese than controls. Mean body mass index at ascertainment was 28.4 for male hypertensives compared with 26.5 for controls, and 26.9 for female hypertensives compared with 22.8 for controls, differences highly significant for men $(p<0.001)$, less so for women $(p<0 \cdot 01)$.

Obesity increased equally in all groups over the 20 years or so of follow up, despite sustained medical advice but without help from a dietitian. Group mean body mass index in hypertensive men rose from 28.4 to 29.4 , and in controls from $26 \cdot 4$ to $27 \cdot 4$. Mean body mass index in hypertensive women rose from 26.9 to $27 \cdot 6$, and in controls from $22 \cdot 8$ to $23 \cdot 5$.

\section{ASSOCIATED CARDIOVASCULAR RISKS}

All young hypertensives were given repeated advice and support on associated or causal risks for coronary disease, particularly smoking. Controls were given similar advice at routine consultations, but this was generally less systematic, sustained, or reinforced unless they had respiratory symptoms. The proportion of stated smokers among male hypertensives fell from an initial 17 of the 25 to eight, and in controls from 17 of 25 to 10 . Smoking in women was virtually unchanged, starting at eight of the 16 in hypertensives and seven of 16 in controls, and ending at six of 16 and seven of 16 respectively.

For blood cholesterol concentrations too few controls had contemporary measurements to allow valid com- parisons, but attempts to reduce cholesterol by dietary advice in cases were generally unsuccessful.

\section{Discussion}

There is little evidence from controlled trials in this age group from which to assess either the value of treatment with antihypertensive drugs or their cumulative risk when taken for a remaining lifetime of 60 years or more. Our treatment policies in this age group were conservative, particularly in the first 10 years. However, all deaths and most of the considerable arterial damage occurred where pressures were uncontrolled, poorly controlled, or treatment was delayed until there was evidence of organ damage, largely because aggressive prescription of tolerable drugs only gradually became accepted practice in the late 1960s and early 1970s. Our four hypertension related male deaths all occurred in the first 12 years of the 21 years of follow up, suggesting their treatment was probably begun too late.

Multifactorial assessment of risks and patient education are of special importance in this age group, with an emphasis on patient education, smoking, body weight, and blood cholesterol control in management plans which should include exercise programmes and reduction in dietary fat. ${ }^{17}$

The excess of male over female cases found in this age group is consistent with epidemiological studies ${ }^{2}$ but is still not generally appreciated in either hospital or primary care. Young women consult more often and are more likely to have their blood pressure measured, particularly during pregnancy and contraception.

Our data understate incidence because our population included many over 40 whose blood pressures under 40 had never been recorded when our screening policy began in 1968, as well as others who migrated into the practice aged over 40 without previous recorded measurements. As an order of magnitude we found 25 male and 16 female hypertensives under 40 on our definition in a mean population of about 1900 of all ages (227 men and 213 women aged 20-39) over 21 years. This gives five year detection rates of at least $26 / 1000$ for men and $18 / 1000$ for women in the age group $20-39$, so high arterial pressure in young adults is much commoner than has generally been supposed. Practices with less stable populations would have to run shorter cycles to achieve similar detection rates. Some inner city practices now have annual turnovers over $30 \%$. In all practices without a screening or case finding programme with high response most of these cases will not be detected until they are over 40 .

\section{ORAL CONTRACEPTIVES AND ALCOHOL}

Oral contraceptives have been a common and important cause of secondary hypertension, which may become irreversible and occasionally lethal. ${ }^{18}$ Cases reported here were associated with $50 \mu \mathrm{g}$ oestrogen combined pills, mostly before this risk was recognised; it remains to be seen whether $30 \mu \mathrm{g}$ pills are safer, but as the progestogen component may carry a greater hypertensive risk than the oestrogen component ${ }^{13}$ all cases still need careful follow up at not less than three monthly intervals. Even with structured A4 records, computerised recall and repeat prescribing, and a relatively vigilant team, we still found it difficult to ensure that women who had stopped the pill because of a rise in pressure did not resume it, even when they and practice staff were apparently aware of the risk.

High alcohol intake is an important cause of treatment failure in hypertension, as much because of poor compliance with medication or beer promoted obesity as from direct effects on blood pressure. Though we found little evidence of heavier drinking in our cases compared with controls (mean stated intake 46.3 
against 40.5 units/week), a causal role for alcohol has clearly been established by larger studies. ${ }^{12}$ The extent of alcohol problems in this age group is surprising but probably typical of other areas of declining heavy industry and high unemployment.

LESSONS FOR PRACTICE ORGANISATION

Case finding was assisted by the high contact rate in young men characteristic of mining and former mining communities. ${ }^{19}$ We strongly agree with others ${ }^{20}$ who have found better coverage, motivation, and compliance where proactive care is developed from consultation prompted by patient demand than in screening clinics. Our relatively good results for reduced smoking in men suggest this may be an important conclusion. There is consistent evidence that response to well man and similar health promotion clinics is inversely related to social class and that such clinics therefore fail to address problems of prevention and management of chronic disease where need is greatest and anticipatory care could be most effective. ${ }^{21-24}$ Such clinics burgeoned under the 1991 general practitioner contract, but there is no evidence that they detect or deal with disease more effectively than case finding within ordinary consultations. ${ }^{25}$ In our experience initial screening is relatively easy. The hard work begins with effective lifelong follow up, for which separate clinics seem to be essential for efficient division of labour, and detection and control of drop outs.

We are grateful to our parent unit, the Medical Research Council Epidemiology and Medical Care Unit at Northwick Park, directed by Professor Tom Meade, and to Dr Helen Wilkes for advice on statistics. Opinions expressed in this paper do not represent those of the MRC. Some of our costs have been met by a grant from the British Heart Foundation.

1 Widimsky J, Jandova R. Long term prognosis in juvenile hypertension condition after 20 and 28 years. Casopis Lekarsu Ceskych 1980;119:1185.

2 Miall WE, Chinn S. Blood pressure and aging: results of a 15-17 year follow-up study in south Wales. Clin Sci Mol Med 1973;45:23-33s.
3 Morrell DC. Role of research in development of organisation and structure of general practice. $B M F$ 1991;302:1313-6.

4 Heller RF, Rose G. Current management of hypertension in general practice. BMF 1977; :1442-4.

$5 \mathrm{Kurji} \mathrm{KH}$, Haines AP. Detection and management of hypertension in general practices in north west London. BMF 1984;288:903-6.

6 Smith WCS, Lee AJ, Crombie IK, Tunstall-Pedoe H. Control of blood pressure in Scotland: the rule of halves. BMF 1990;300:981-3.

7 Shaper AG, Pocock SJ, Walker M, Cohen NM, Wales CJ, Thomson SG. British regional heart study: cardiovascular risk factors in middle-aged men in 24 towns. $B M Y$ 1981;283:179-86.

8 Hart JT. Distribution of mortality from coronary heart disease in south Wales. $\exists R$ Coll Gen Pract 1970;19:258-68.

9 Hart JT. The marriage of primary care and epidemiology. $f R$ Coll Physician Lond 1974;8:299-314.

$10 \mathrm{Hart} \mathrm{JT}$. Semicontinuous screening of a whole community for hypertension. Lancet 1970;ii:223-6.

11 Beevers DG. Alcohol and hypertension. Lancet 1977;ii:111-4.

12 Arkwright PD, Beilin LJ, Rouse I, Armstrong BK, Vandongen R. Effects of alcohol use and other aspects of lifestyle on blood pressure levels and prevalence of hypertension in a working population. Circulation 1982;66: 60-6.

13 Weinberger MH, Weir RJ. Oral contraceptives and hypertension. In Robertson JS, ed. Handbook of hypertension. Vol 2. Clinical aspects of secondary hypertension. Oxford: Elsevier, 1983:196-207.

14 Wadsworth MEJ, Cripps HA, Midwinter RE, Colley JRT. Blood pressure in a national birth cohort at the age of 36 related to social and familial factors smoking, and body mass. BMF 1985;291:1534-8.

15 Bjorntorp P. Obesity and the risk of cardiovascular disease. Ann Clin Res $1985 ; 17: 3-9$.

16 Hart JT, Thomas C, Gibbons B, Edwards C, Hart M, Jones J, et al. Twentyfive years of audited screening in a socially deprived community. $B M$ 1991;302:1509-13.

17 Hart JT. Coronary heart disease prevention in primary care: seven lessons from three decades. Fam Pract 1990;7:288-94.

18 Zech P, Riffle G, Lindner A, Sassard J, Blanc-Brunat N, Traeger J. Malignan hypertension with irreversible renal failure due to oral contraceptives. $B M$ 1975;iv:326-7.

19 Hart JT. General practice workload, needs, and resources. $f R$ Coll Gen Pract 1976;26:885-92.

20 Main J, Main P. Problematical models-targets and clinics. RCGP Connection 1990 Sept:4-5.

21 Pill R, French J, Harding K, Stott N. Invitation to attend a health check in a general practice setting: comparison of attenders and non-attenders. $\exists R$ Coll Gen Pract 1988;38:53-6.

22 Pill $R$, Stott $N$. Invitation to attend a health-check in a general practice setting: the views of a cohort of non-attenders. $\mathcal{F}$ C Coll Gen Pract 1988;38:57-60.

23 Thompson NF. Inviting infrequent attenders to attend for a health check: costs and benefits. $\mathrm{Br} \mathcal{I}$ Gen Pract 1990;40:16-8.

24 Waller D, Agass M, Mant D, Coulter A, Fuller A, Jones L. Health checks in general practice: another example of inverse care? $B M \mathcal{F} 1990 ; 300: 1115-8$. 25 Fowler G, Mant D. Health checks for adults. BMF 1990;300:1318-20.

(Accepted 9 December 1992)

\section{The killing speeds}

I had noticed the blunt statement often enough on billboards, in newspapers, at garages-"Speed Kills"and the statistics. Which? magazine (October 1992) reported that $85 \%$ of pedestrians struck by a car at $40 \mathrm{mph}$ were killed, while at $20 \mathrm{mph}, 95 \%$ survived. I accepted this as true and important without giving much attention to it until it occurred to me to try driving at only $20 \mathrm{mph}$ for a while to see what it felt like. In suburban streets, when you are continually slowing for a corner, stopping at traffic lights, or before turning into a busy major road, $20 \mathrm{mph}$ may well be an average speed anyway. Would that average be much reduced by making $20 \mathrm{mph}$ the upper limit? I therefore tried regarding all $30 \mathrm{mph}$ limits as meaning $20 \mathrm{mph}$.

Naturally, I had to make exceptions-for example, when I was followed by a speeding ambulance in a road where it was not possible to draw in to allow it to pass would accelerate until I reached a suitable spot. I took pains to avoid being a real inconvenience to other drivers, but, in general, for about a week, I stuck to my self imposed speed limit. I anticipated and got a few black looks and heard a few impatient horns, but I quite enjoyed it. The increase in the time it took me to get to various destinations in or near my home town was negligible.

The busy general practitioner with a large visiting list to get through before afternoon surgery may well call this a counsel of perfection, and no one is likely to loiter on the way to a possible cardiac arrest. But perhaps we doctors could give a lead in this particular aspect of road safety? After all, it is our patients who are getting killed.-DENIS CASHMAN is a retired general practitioner in Cullercoats, Tyne and Wear

We are delighted to receive submissions of up to 600 words on $A$ paper (or patient or book) that changed my practice, $A$ memorable patient, The one message I would like to leave behind, or related topics. 